\title{
Léxico COVID, Segunda parte
}

COVID Lexicon, Part Two

\author{
Oscar G. Pamo Reyna
}

\section{ANTIVACUNA}

Movimiento conformado por personajes diversos, desde hombres de ciencia hasta estrafalarios, opuestos a la vacunación contra el COVD-19 aduciendo argumentos sin solidez científica.

\section{CERCO EPIDEMIOLÓGICO}

Restricción de la circulación, entradas y salidas, en un área geográfica determinada como medida de contención para la propagación del SARS-CoV-2. Esta medida se toma ante el creciente número de infectados, de hospitalizados y de muertos de COVID-19. Este cerco puede ser de una región o departamento, como fue el caso de la región Arequipa en el mes de junio del presente año, o puede ser de un área dentro de una ciudad como se hizo algunas veces en China y países europeos.

\section{CONFINAMIENTO}

Vocablo de uso extendido por el público y la prensa. EL DLE lo define correctamente:

1 Médico internista. Profesor principal, Facultad de Medicina, Universidad Peruana Cayetano Heredia, Lima, Perú.

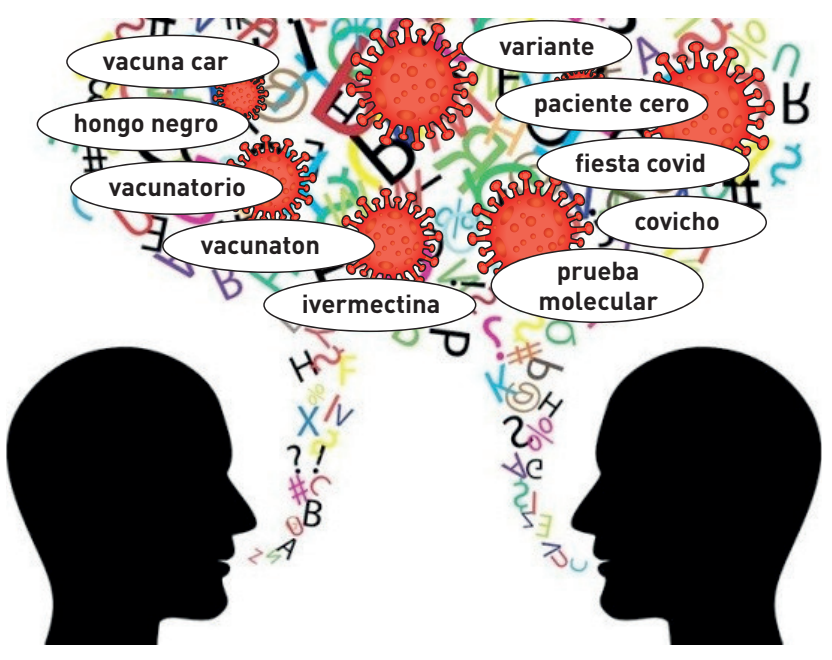

aislamiento temporal y generalmente impuesto de una población, una persona o un grupo por razones de salud o de seguridad.

\section{CORONAFOBIA}

Estado de ansiedad disfuncional desencadenado exclusivamente por la pandemia de coronavirus: por haber sido diagnosticado de COVID-19, de tener un familiar enfermo o infectado de COVID-19, por la permanente exposición a la información sobre la enfermedad, el confinamiento y el desempleo. 
Un estudio local reveló que el 13\% de la población adulta mayor lo padecía, especialmente los que se encontraban en la primera línea de batalla contra el coronavirus, $42 \%$, como profesionales de la salud, policías, bomberos, etc. ${ }^{1}$

\section{COVICHO}

El DLE ya lo registra como de uso coloquial desde abril del 2020 para referirse al SARS-CoV-2, causante de la COVID-19. Entrecruzamiento de CoVid y bicho. También recoge la grafía de cobicho. ${ }^{2}$

\section{COVIDIOTA}

Del inglés CoVidiot, de CoVid e idiot, para denotar a la persona que desoye o no sigue las medidas preventivas para evitar el contagio por el SARS-CoV-2. El vocablo CoVidiot fue recogido por el Oxford Advanced Lerarner's Dictionary en el 2020 y por el Diccionario histórico de la lengua española, de la RAE, en el 2021..$^{3,4}$

\section{COVID PERSISTENTE}

COVID-19 persistente, CoVid persistente, o Long COVID en inglés, es una condición clínica que se ha reconocido en la medida que la pandemia COVID-19 ha evolucionado y ha permitido conocer parte de su historia natural. Se refiere a cuando las personas presentan síntomas y signos que se desarrollan durante o después de una infección compatible con la COVID-19, y que se mantienen durante más de 4 a 12 semanas y que no se explican por un diagnóstico alternativo. Por lo menos un 10 $\%$ de los afectados por la infección aguda tendrá persistencia de los síntomas más allá de la semana 12. ${ }^{5,6}$ Estas secuelas ha llevado a que se establezcan algunas guías para el reconocimiento y manejo de este síndrome.

\section{DIÓXIDO DE CLORO}

El dióxido de cloro $\left(\mathrm{ClO}_{2}\right)$ es una sustancia química muy usada como desinfectante en superficies, alimentos y tratamiento de aguas de consumo humano y en aguas residuales, y como blanqueador en la industria del papel, entre otras aplicaciones. Se ha demostrado su efecto como desinfectante contra el virus SARS-CoV-2 y otros virus; sin embargo, no existe evidencia científica que avale su administración por vía oral para la prevención o tratamiento del COVID-19.

\section{FIESTA COVID}

Se denomina así a las reuniones festivas o celebraciones -como juergas, bautizos, cumpleaños, matrimonios, etc.- realizadas durante la pandemia, contraviniendo la recomendación de aislamiento físico. Aquellas detectadas o denunciadas son intervenidas por la policía por ser consideradas como fuentes de contagio del coronavirus.

\section{HISOPAR}

El DLE define hisopar como rociar con el hisopo. Y, rociar como esparcir en gotas menudas agua u otro líquido Pero, en realidad hisopar no significa estas acciones sino la de empapar o humedecer el hisopo, que es lo que se hace con las secreciones nasofaríngeas para realizar las pruebas diagnósticas, como la prueba molecular y la antigénica en la detección del SARS-CoV-2.

\section{HONGO NEGRO}

En las últimas semanas, la prensa viene llamando la atención por la aparición de una enfermedad infecciosa como complicación del COVID-19 y la denominó como hongo negro -en inglés, black fungus- y es para referirse a lo que conocemos como mucormicosis. Esta micosis suele producir un tejido necrótico negruzco, de allí la denominación, y afecta la región rino-orbital y puede extenderse al cerebro. ${ }^{7}$

Hay un incremento de informes sobre casos de mucormicosis asociada a la COVID-19 (CAM, COVID-19 associated mucormycosis) principalmente en personas con diabetes mellitus, cetoacidosis diabética o en tratamiento con inmunosupresores. El mayor número de casos ha sido notificado en la India, donde se estima que hay más de 4000 personas con CAM y en las Américas, 
la OMS registra nueve casos al 09-06-2021.8 En realidad, existe subregistro; así, en nuestro medio fueron reportados cuatro casos a fines del año pasado. ${ }^{9}$

\section{IVERMECTINA}

Es el nombre genérico de un fármaco que ha estado en boca del común de los mortales en todas partes, además de la prensa escrita y científica. Es un reconocido antiparasitario que en el laboratorio mostró cierta actividad contra el SARS-CoV-2 por lo que se extrapoló dicho efecto para prevenir y tratar la COVID-19. A la fecha, no hay ninguna evidencia científica de su supuesto efecto benéfico en la lucha contra la COVID-19, tanto para la profilaxis como el tratamiento de los sintomáticos, sean estos leves o graves.

\section{OXÍGENO MEDICINAL}

Es el oxígeno gas a concentración de más del $99,5 \% \mathrm{v} / \mathrm{v}$ comprimido a una presión de 200 bar $\left(15^{\circ} \mathrm{C}\right)$, empleado en la corrección de la hipoxemia de distintos orígenes que requieren de la administración de oxígeno a presión normal o elevada, la alimentación de los respiradores en anestesia y reanimación, y la administración de medicamentos mediante nebulizador.

$\mathrm{Su}$ necesidad evidenció las falencias de los sistemas de salud, en mayor o menor medida, en la región y gran parte del mundo durante la pandemia: las dificultades para garantizar la provisión adecuada de oxígeno medicinal para $15 \%$ de los pacientes con COVID-19, que según la Organización Mundial de la Salud lo requerirá en algún momento durante la hospitalización y eventualmente luego del alta.

$\mathrm{Su}$ gran demanda durante la pandemia COVID-19 puso de manifiesto situaciones dramáticas para conseguirlo y paliar la hipoxemia severa de los afectados.

\section{PASAPORTE COVID}

Certificado, digital o papel, de estar vacunado contra la COVID-19 exigido por algunos países para permitir el ingreso a sus territorios, como una medida de contener la propagación del SARS$\mathrm{CoV}-2$, especialmente de las variantes de interés.

Con la llegada de la tercera ola, especialmente con la variante delta, varios países europeos y estados norteamericanos empezaron a exigir este certificado de vacunación para asistir a centros con alta concentración de personas, lo cual originó manifestaciones de protestas por muchos que lo consideraron como una imposición contra sus derechos ciudadanos.

\section{PONGO EL HOMBRO}

Nombre de la campaña publicitaria llevada a cabo desde que se dispuso de la vacuna y para incentivar a la población se vacune. En dicha campaña se recurrió a médicos, enfermeras, pacientes y personajes públicos para contrarrestar las opiniones antivacunas.

\section{PROTECTOR FACIAL}

Careta de material transparente, como el policarbonato, utilizada como una barrera adicional, además de la mascarilla única o doble, para la prevención del contagio por el SARS-CoV-2.

\section{PRUEBA ANTIGÉNICA}

Esta es una prueba rápida y fiable para la detección cualitativa de antígenos del SARS-CoV-2 presentes en la nasofaringe humana mediante un inmunoensayo cromatográfico. Muy útil en los primeros días de infección.

\section{PRUEBA MOLECULAR}

Para la detección del virus SARS-CoV-2, en la muestra del hisopado nasofaríngeo se emplean las pruebas de conversión del ARN vírico en $\mathrm{ADN}$ con la enzima transcriptasa inversa. El ADN así conseguido es sometido a amplificación (mediante la reacción en cadena de polimerasa) y cuantificado en tiempo real mediante sondas fluorescentes, de tal modo que existe una relación directamente proporcional entre la cantidad de fragmentos de ADN que se están formando y el grado de fluorescencia. El proceso dura horas por lo que los 
resultados se obtienen después de unas 48 horas de iniciada la prueba.

Entonces, la prueba molecular se refiere a la prueba RT-PCR (real time-polimerase chain reaction) para el SARS-CoV-2.

\section{PRUEBA RÁPIDA}

Prueba basada en la detección de anticuerpos IgG e IgM mediante exámenes inmunocromatográficos o de inmunoensayo de flujo lateral, sencillos y muy fáciles de realizar. Se le llama rápida porque permite obtener resultados en unos 15 minutos. Tiene muy baja sensibilidad para el diagnóstico de infección por SARS-CoV-2. Su mejor uso es para determinar la prevalencia de la infección por SARS-CoV-2 en una población.

\section{SEGUNDA OLA}

Término muy usado en el lenguaje popular y la prensa. En los casos de epidemias, o pandemias, la representación gráfica del número de casos o contagiados a través del tiempo nos muestra curvas ascendentes que llegan a un tope y luego son descendentes hasta alcanzar un mínimo o basal prepandémico. Secuencialmente, el recrudecimiento de la epidemia puede mostrarnos una curva similar a la anterior, pudiendo ser mayor, igual o menor en intensidad. De aquí, que figurativamente se hable de una "segunda ola".

\section{TELECONSULTA}

Atención médica mediante una plataforma virtual (ej. Zoom, Teams, etc.) o por teléfono. La pandemia obligó al cierre del primer nivel de atención de salud o restringió el acceso a los servicios de emergencias de los hospitales, que se hallaban desbordados por los pacientes con COVID-19, por lo que buena parte de la población recurrió a esta modalidad de atención. Los hospitales y clínicas también implementaron este sistema para cubrir la demanda de la población. Del mismo modo, los pagos de las consultas, cuando correspondía, se hicieron por transferencia interbancaria.

\section{TELEMONITOREO}

Hacer el seguimiento de las manifestaciones de una enfermedad -como el COVID-19- un tratamiento o la convalecencia de un paciente mediante telefonía $\mathrm{u}$ otros medios informáticos (como las redes sociales, plataformas virtuales, etc.).

\section{TELEORIENTACIÓN}

Acción y efecto de orientar mediante teléfonos o medios informáticos (como las redes sociales, plataformas virtuales, etc.).

\section{TURISMO DE VACUNAS}

Ante el déficit de vacunas para satisfacer las necesidades de la población, muchos individuos optaron por viajar al exterior como simples turistas para conseguir ser vacunados contra el COVID-19, ya que de lo contrario tendrían que esperar un buen tiempo hasta que les corresponda vacunarse. Así, mucha gente, sin la condición de residente, viajó a los EE.UU. de Norteamérica, especialmente, para vacunarse

\section{VACUNACAR}

O, vacuna car, vacunaCar, vacuna Car.

Aquel servicio de vacunación contra el COVID-19 provisto en el auto. Este servicio se ofrece a las personas que ingresan al centro de vacunación en un auto y son vacunados sin necesidad de descender del mismo. ${ }^{10}$

\section{VACUNA MOVIL}

Estrategia de llevar las dosis de las vacunas contra la COVID-19 y a las brigadas de vacunación en taxis o mototaxis, lo que permite acceder a zonas alejadas, elevadas o de difícil acceso de la ciudad. La finalidad es acercar las vacunas a la población vulnerable mediante visitas casa por casa.

\section{VACUNATÓN}

Estrategia desarrollada para abarcar la mayor población en las jornadas de inmunización 
contra el COVID-19, consistente en programar vacunaciones en diferentes centros durante 36 horas ininterrumpidas, incluso durante el horario del toque de queda. ${ }^{11}$

\section{VACUNATORIO}

Centro donde se aplica la vacuna para el COVID-19. Muy usado entre nosotros, especialmente con la prensa hablada y escrita. Vocablo no reconocido en el DLE.

\section{VACUNÓMETRO}

Medición o cuantificación y datos estadísticos de los vacunados. Así, el Colegio Médico del Perú lleva el conteo del personal médico vacunado en el país. $^{12}$

\section{VARIANTE}

La cepa inicial del coronavirus SARS-CoV-2 de Wuhan ha venido mutando en su desplazamiento por el resto del mundo. Estas mutaciones son comunes en los virus y cada una de ellas viene a ser una variante. Muchas veces, estas variantes dan origen a cepas con alguna ventaja que le permita reproducirse con mayor facilidad como también puede suceder lo contrario.

Hasta el momento se han hallado más de 120 variantes del SARS-CoV-2 mediante estudios genómicos en los diversos países por donde ha venido circulando dicho virus. La prensa ha venido dando cuenta de la aparición de estas variantes y suele designarlas con su origen; así la variante británica, sudafricana, brasileña, india, etc. Estas variantes ya tienen una denominación científica por la OMS, para evitar la estigmatización: Alpha (B.1.1.7), Reino Unido; Beta (B.1.351), Sudáfrica; Gamma (P.1), Japón ex Brasil; Delta (B.1.617.2), India; etc. ${ }^{13,14}$

Los Centros para el Control y la Prevención de Enfermedades (CDC, Centers for Disease Control and Prevention) han designado tres niveles de variantes: variantes de interés, variantes de preocupación y variantes de altas consecuencias. ${ }^{15}$

\section{VARIANTE DELTA}

$\mathrm{O}$, variante India (B.1.617.2), es el linaje viral de SARS-CoV-2 que apareció en la India durante el feroz ataque de la COVID-19 en los meses de mayo y junio del 2021. En los meses siguientes se detectaron casos de COVID-19 por esta variante en el sudeste asiático, Europa y, gradualmente, en el resto del mundo. Este coronavirus se diferencia de las variantes anteriores por tener una mayor transmisibilidad, generar una enfermedad más grave, afectar niños y jóvenes en mayor proporción $\mathrm{y}$ tener menor cobertura con las vacunas actuales.

\section{VARIANTE DE ALTA CONSECUENCIA}

Aquella variante que demuestra claramente que las medidas de prevención o las contramedidas médicas han reducido significativamente su eficacia en relación con las variantes que circulaban anteriormente. En el momento actual. No hay ninguna cepa del SARS-CoV-2 catalogada como variante de alta consecuencia. ${ }^{15}$

\section{VARIANTE DE INTERÉS}

Aquella variante con marcadores genéticos específicos que se han asociado con cambios en la unión a los receptores, una neutralización reducida por anticuerpos generados contra una infección o vacunación previa, una menor eficacia de los tratamientos, un posible impacto diagnóstico o un aumento previsto de la transmisibilidad o la gravedad de la enfermedad. Así, las variantes Eta, Iota, y Kappa. ${ }^{15}$

\section{VARIANTE DE PREOCUPACIÓN}

Aquella variante para la que hay evidencia de un aumento en la transmisibilidad, una enfermedad más grave (por ejemplo, un incremento de las hospitalizaciones o muertes), una reducción significativa en la neutralización por anticuerpos generados durante la infección o la vacunación previa, una menor efectividad de los tratamientos o vacunas, o fallas en la detección de diagnósticos. Así, las variantes Alfa, Beta, Delta y Gamma. ${ }^{15}$ 


\section{VARIANTE LAMBDA}

$\mathrm{O}$, variante andina. Detectada en Lima, Perú, en diciembre del 2020. Para agosto del 2021 es el causante del 90\% de los casos de COVID-19 en el país.

\section{Referencias bibliográficas}

1. Nuevos estudios buscan frenar el COVID19. El Comercio, jueves 3 de junio del 2021, página 13.

2. https://www.rae.es/dhle/CoVicho

3. Gutiérrez, Czar. Nuevos usos (y abusos) léxicos en tiempos de pandemia. El Comercio, Luces. Martes 4 de mayo del 2021: 2.

4. https://www.rae.es/dhle/CoVidiota

5. Oronsky B, Larson C, Hammond TC, Oronsky A, Kesari S, Lybeck M, Reid TR. A review of persistent post-COVID syndrome (PPCS). Clin Rev Allergy Immunol. 2021 Feb 20:1-9. doi: 10.1007/ s12016-021-08848-3. Epub ahead of print. PMID: 33609255; PMCID: PMC7896544.

6. Guía clínica para la atención al paciente long COVID/COVID persistente. URL disponible en: https://www.semg.es/images/2021/ Documentos/GUIA_CLINICA_COVID_Persistent_20210501_ version final.pdf

7. Sumanth Gandra, Sanjay Ram, Stuart M. Levitz. The "Black Fungus" in India: The Emerging Syndemic of COVID-19Associated Mucormycosis. Ann Intern Med. [Epub ahead of print 8 June 2021]. doi:10.7326/M21-2354

8. OPS. Alerta Epidemiológica. Mucormicosis asociada a la COVID-19. 11 de junio de 2021. URL disponible en: https://www.paho.org/es/ documentos/alerta-epidemiologica-mucormicosis-asociadaCoVid-19
9. Elguera-Falcón, F., \& Cumpa-Quiróz, R. (2020). Mucormicosis en pacientes diabéticos post infección por COVID-19. Revista de la Sociedad Peruana de Medicina Interna, 33(4), 176-182. https://doi. org/10.36393/spmi.v33i4.568

10. La Costa Verde contará con dos 'vacunacar'. El Comercio, 5 de junio del 2021, pág. 12.

11. Redacción. ¿Qué es el vacunatón? Ministro adelante detalles sobre esta estrategia de inmunización contra el COVID-19. Gestión. Lima, 1 de julio del 2021.

12. https://www.cmp.org.pe/vacunometro-cmp/

13. WHO. WHO announces simple, easy-to-say labels for SARS-CoV-2 variants of interest and concern. URL disponible en: https://www. who.int/news/item/31-05-2021-who-announces-simple-easy-to-saylabels-for-sars-CoV-2-variants-of-interest-and-concern

14. European Centre for Disease Prevention and Control. SARS-CoV-2 variants of concern as of 3 June 2021. URL disponible en: https:// www.ecdc.europa.eu/en/CoVid-19/variants-concern

15. CDC. SARS-CoV-2 Variant Classifications and Definitions. Updated August 24 $4^{\text {th }}$ 2021. URL disponible en: https://www.cdc.gov/ coronavirus/2019-nCoV/variants/ variant-info.html

\section{Correspondencia:}

\section{Oscar G. Pamo-Reyna, oscar.pamo@upch.pe}

Fecha de recepción: 20-06-2021.

Fecha de aceptación: 20-08-2021.

Conflicto de interés: ninguno, según el autor.

Financiamiento: por el autor. 